\title{
Monitoring Stabilitas Transien Pada Sistem Tenaga Listrik
}

\author{
Transient Stability Monitoring in Electric Power Systems
}

\author{
Dian Nova Kusuma Hardani ${ }^{*}$, Abi Aditya Triyanda ${ }^{2}$, Winarso ${ }^{3}$ \\ 1,2,3)Program Studi Teknik Elektro, Fakultas Teknik dan Sains \\ Universitas Muhammadiyah Purwokerto \\ Jl. Raya Dukuh Waluh, Kembaran 53182, Indonesia. \\ email: ${ }^{* 1}$ diannova.kh@ump.ac.id, ${ }^{2}$ abiaditya95@gmail.com, ${ }^{3}$ ewinarso@gmail.com
}

\begin{abstract}
DOI:
10.30595/jrst.v3i2.4686

Kebutuhan listrik pada saat ini merupakan kebutuhan primer bagi masyarakat Indonesia, sehingga kualitas energi listrik yang baik harus dipenuhi. Perubahan beban yang bervariatif dapat berdampak pada

Histori Artikel: kestabilan sistem. Jika terjadi peristiwa beban berlebih atau gangguan

Diajukan:

$01 / 07 / 2019$ maka harus dilakukan pelepasan beban agar system tetap stabil. Peristiwa alih hubung pada rangkaian listrik dapat menyebabkan adanya sentakan tegangan dan arus yang disebut dengan arus transien. Pada

Direvisi:

$24 / 09 / 2019$

Diterima: $25 / 09 / 2019$ penelitian ini, analisis perhitungan dan simulasi lepasnya pembebanan di Gardu Induk menggunakan perangkat lunak ETAP. Hal ini berguna untuk mengetahui seberapa stabil transien yang muncul akibat adanya pelepasan beban dan jumlah kerugian yang diakibatkan oleh gangguan tersebut. Berdasarkan hasil tersebut diperoleh tegangan pulih akibat transien sekitar 3 detik setelah terjadi pelepasan salah satu power grid Gardu Induk Kalibakal kemudian sekitar 0,2 detik saat pelepasan beban di feeder 11 dan 14. Hasil tersebut menunjukkan bahwa kestabilan transien pada sistem tenaga listrik di Gardu Induk Kalibakal masih dalam kondisi baik.
\end{abstract}

Kata Kunci: transien, beban, tegangan, ETAP, gangguan.

\begin{abstract}
Electricity needs at this time are a primary need for the people of Indonesia so that the quality of good electrical energy must be met. Variable load changes can have an impact on system stability. If an event of overload or disturbance occurs, the load must be removed so that the system remains stable. The event of a switch on an electric circuit can cause a voltage, and current jolt called a transient current. In this study, analysis of calculation and simulation of load release at the Substation uses ETAP software. It is useful to find out how stable the transients are due to the release of the load and the amount of loss caused by the disturbance. Based on these results, the transient recovery voltage is obtained about 3 seconds after the release of one of the Kalibakal substation power grids, then about 0.2 seconds during load release in feeders 11 and 14. The results show that the transient stability in the electric power system in the Kalibakal Substation still in good condition.
\end{abstract}

Keywords: transient, load, voltage, ETAP, disturbance.

\section{PENDAHULUAN}

Kebutuhan listrik di Indonesia semakin meningkat. Listrik merupakan energi yang sangat berpengaruh dalam kehidupan manusia. Oleh karena itu, kualitas energi listrik yang baik haruslah dipenuhi agar kebutuhan konsumen terpenuhi. Perubahan beban yang bervariatif berdampak pada kestabilan sistem. Jika daya 
mekanik pada poros penggerak awal tidak dengan segera menyesuaikan dengan besarnya daya elektrik pada beban listrik, maka frekuensi dan tegangan akan bergeser dari posisi normal (Tambunan, Karnoto, \& Handoko, 2014). Penyebab pelepasan beban terjadi karena gangguan, perbaikan jaringan ataupun pasokan listrik dari pembangkin mengalami drop atau terjadi kerusakan pembangkit yang menyebabkan pemutusan jaringan ke gardu induk maupun ke konsumen.

Salah satu peralatan yang listrik yang dampaknya sangat berpengaruh terhadap gangguan ataupun alih hubung (swiching) yang menyebabkan timbulnya kestabilan transien adalah transformator. Transformator adalah suatu alat untuk memindahkan daya listrik arus bolak - balik dari suatu rangkaian ke rangkaian lainya secara induksi elektro magnetik. Terjadinya gangguan dan pelepasan beban (load sheeding) mengakibatkan kestabilan transien pada jaringan mengalami perubahan drastis yang mengakibatkan kerusakan peralatan yang cukup merugikan. Analisis kestabilan transien memiliki dampak besar pada perencanaan dan pengoprasian sistem tenaga listrik (Popov, Yorino, Zoka, Sasaki, \& Sugihara, 2014).

Peristiwa alih hubung pada suatu rangkaian listrik menyebabkan adanya sentakan tegangan dan arus yang disebut dengan arus transien. Saat terjadi transien komponenkomponen mengalami tekanan yang sangat besar berupa tegangan dan arus terutama pada transformator yang mensuplai beban, hal ini menyebabkan penurunan waktu kerja transformator tersebut (Ri'ayatullah \& Waluyo, 2013). Arus transien mengakibatkan kerusakan pada transformator khususnya pada belitannya serta dapat menurunkan kehandalan transformator. Namun, masih aman untuk circuit breaker sedangkan untuk tegangan transien masih aman untuk transformator tetapi dapat menyebabkan kerusakan pada peralatan kendali elektronik (Prayitno, 2013). Penelitian tentang analisis kestabilitas transien dan mekanisme pelepasan beban pada generator outage, motor starting dan hubung singkat juga pernah dilakukan (Hidayat, Priyadi, \& Pujiantara, 2013) dan (Ariansyah, Priyadi, \& Pujiantara, 2016) dengan melihat respon sudut rotor, frekuensi dan tegangan dari simulasinya. Sedangkan penelitian analisis stabilitas transien dan pelepasan beban pada jaringan transmisi sistem tenaga listrik dilakukan (Winarso \& Yunarto, 2017) dan
(Defariza, Soeprijanto, Lystianingrum, \& Putri, 2011) menggunakan aplikasi Electric Transient and Analysis Program (ETAP) dalam pembuatan simulasinya. Hasil menunjukkan bahwa aplikasi ETAP dapat digunakan untuk menganalisis kestabilan tegangan dan kestabilan frekuensi, serta pelepasan beban (load shedding) saat terjadi gangguan generator lepas/trip, starting motor berkapasitas besar, hubung singkat pada sisi beban, dan hilangnya eksitasi pada pembangkit.

Berdasarkan hal tersebut di atas, maka perlu dilakukan penelitian dan simulasi pelepasan beban untuk studi kasus lain yaitu mengetahui kestabilan transien pada jaringan distribusi Gardu Induk Kalibakal dengan simulasi program ETAP kemudian dimonitor kestabilannya.

\section{METODE PENELITIAN}

Penelitian dilakukan dengan cara mengumpulkan data secara langsung dan menganalisisnya. Hasil analisis tersebut digunakan untuk mengambil suatu kesimpulan. Kesimpulan tersebut sebagai proses dasar untuk menentukan pengaruh pelepasan beban terhadap kestabilan transien dalam melakukan simulasi pelepasan beban. Data-data yang dikumpulkan berdasarkan pada data-data teknis jaringan distribusi di di PT. PLN (Persero) P3B UPT Purwokerto, Gardu Induk Kalibakal 150/20 KV. Secara garis besar ditunjukkan pada Gambar 1.

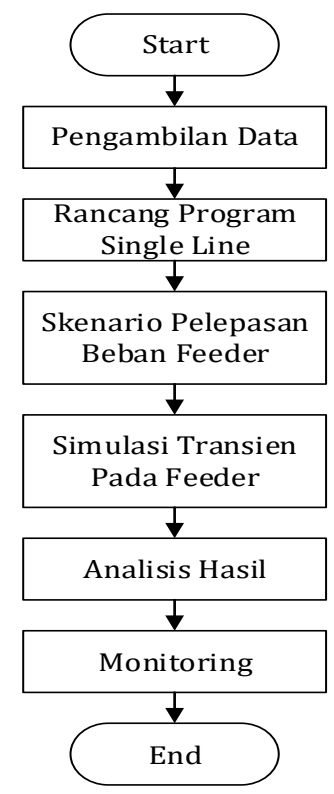

Gambar 1. Jalan Penelitian 


\subsection{Pengambilan Data Jaringan}

Data yang yang dibutuhkan dalam penelitian ini diambil langsung di lapangan setelah mendapatkan ijin dari pihak otoritas yakni APP Purwokerto. Data yang digunakan berupa data real antara lain:

\section{a) Single Line Diagram}

Gardu Iduk Kalibakal menggunakan transformator dengan kapasitas 20 MVA dan 20 MVA dengan tegangan masukan sebesar $150 \mathrm{KV}$ dan tegangan keluaran sebesar $20 \mathrm{KV}$. Gardu Unduk kalibakal mempunyai 16 feeder untuk mendistribusikan listrik ke area cakupannya.

b) Data Setting Over Load Relay (OLR) dan Under Frequency Relay (UFR)

Pada dasarnya OLR dipasang secara seri dengan trafo arus. Hal ini dimaksudkan untuk membandingkan besarnya arus pada sisi sekunder trafo dengan arus acuan/setting. Besarnya arus setting OLR dapat dihitung dari rasio trafo arus. OLR dikoordinasikan dengan PMT $20 \mathrm{KV}$ pada setiap feeder. Besarnya arus acuan dari hasil perhitungan sisi sekunder trafo arus yang diperoleh akan meningkat. Jika arus meningkat melebihi arus acuannya maka PMT akan terbuka/trip. Pada pengaturan ini, OLR yang digunakan berupa relay elektronik dari SIMENS Tipe 7SD52/53. Penggunaan relay ini dikarenakan karektiristik kerja relay yang dapat digunakan sebagai pengaman short circuit dan overhead pada line transmission.

UFR dipasang secara seri dengan trafo tegangan. Cara kerja UFR adalah jika frekuensi pada system di bawah frekuensi pengaturannya, maka relay akan bekerja memutus PMT pada feeder yang menjadi target. UFR dikoordinasikan dengan PMT pada tiap feeder. Besarnya frekuensi UFR adalah 48,2 Hz dan $48 \mathrm{~Hz}$. Jika frekuensi ini terpenuhi maka PMT pada tiap feeder akan terbuka.

c) Data Trafo

Data trafo yang dibutuhkan untuk simulasi adalah trafo tenaga, trafo arus dan trafo tegangan. Adapaun rincian datanya masing-masing trafo berupa kapasitas trafo, impedansi trafo, dan hubungan trafo untuk trafo tenaga. Sedangkan data rasio trafo dan arus acuan dibutuhkan untuk trafo arus.

d) Data Jaringan

e) Data Beban Input

f) Data Beban masing-masing feeder

Selain data tersebut di atas, data pendukung yang dibutuhkan untuk keperluan simulasi berupa data karakteristik beban tiap transformator. Adapun rincian data tiap transformator seperti ditunjukkan pada Tabel 1 berikut.

\subsection{Pembuatan Single Line Diagram}

Single line diagram dibuat berdasarkan data yang telah diperoleh di lapangan. Pembuatannya menggunakan aplikasi ETAP. Dalam aplikasi ETAP terdapat fitur simulasi transien. Adapun bentuk single line diagram yang telah dibuat berdasarkan data real yang ada ditunjukkan pada Gambar 2.

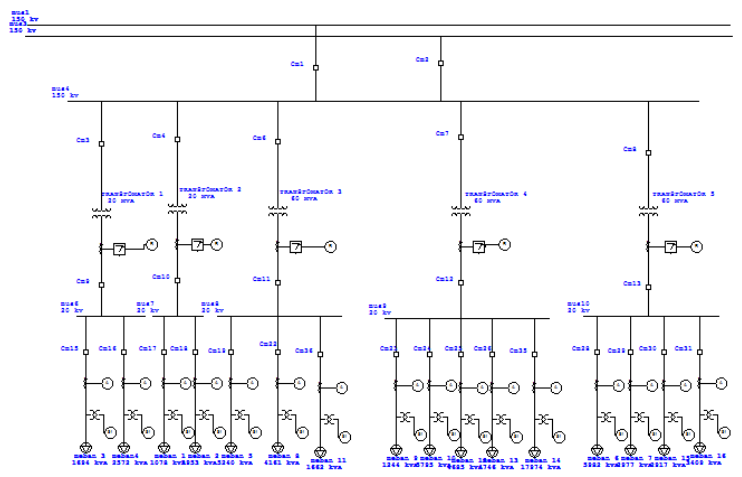

Gambar 2. Single Line Diagram Sistem Distribusi Gardu Induk Kalibakal 
Tabel 1. Konsumsi Daya Listrik pada 1 Januari 2018

\begin{tabular}{|c|c|c|c|c|c|c|c|c|c|c|c|}
\hline \multicolumn{2}{|c|}{$\begin{array}{c}\text { Data } \\
\text { Penyulang }\end{array}$} & \multicolumn{10}{|c|}{ Pukul 10:00 } \\
\hline \multirow{2}{*}{ GI } & \multirow{2}{*}{ Trafo } & \multirow{2}{*}{$\begin{array}{c}\text { Tegangan } \\
\text { KV }\end{array}$} & \multirow{2}{*}{$\begin{array}{c}\text { Daya } \\
\text { MW }\end{array}$} & \multicolumn{3}{|c|}{ Beban INC } & \multirow{2}{*}{ Feeder } & \multicolumn{3}{|c|}{ Beban Feeder (A) } & \multirow{2}{*}{$\begin{array}{c}\text { Cos } \\
\varphi\end{array}$} \\
\hline & & & & $\mathbf{R}$ & $S$ & $T$ & & $\mathbf{R}$ & $\mathbf{S}$ & $\mathbf{T}$ & \\
\hline \multirow{16}{*}{ KBL } & \multirow{2}{*}{$\begin{array}{l}\text { TRAFO I } \\
\text { (20MVA) }\end{array}$} & \multirow{2}{*}{20,4} & \multirow{2}{*}{5,06} & \multirow{2}{*}{164} & \multirow{2}{*}{139} & \multirow{2}{*}{170} & KBL03 & 52 & 43 & 49 & 0,96 \\
\hline & & & & & & & KBL04 & 111 & 87 & 121 & 0,96 \\
\hline & \multirow{2}{*}{$\begin{array}{l}\text { TRAFI II } \\
\text { (20MVA) }\end{array}$} & \multirow{2}{*}{20,2} & \multirow{2}{*}{4,68} & \multirow{2}{*}{158} & \multirow{2}{*}{132} & \multirow{2}{*}{148} & KBL01 & 28 & 20 & 45 & 0,94 \\
\hline & & & & & & & KBL02 & 129 & 110 & 99 & 0,94 \\
\hline & TRAFO & \multirow{3}{*}{20,1} & \multirow{3}{*}{10,19} & \multirow{3}{*}{324} & \multirow{3}{*}{285} & \multirow{3}{*}{341} & KBL05 & 140 & 149 & 162 & 0,94 \\
\hline & \multirow{2}{*}{$\begin{array}{c}\text { III } \\
\text { (60MVA) } \\
\end{array}$} & & & & & & KBL08 & 116 & 98 & 142 & 0,94 \\
\hline & & & & & & & KBL11 & 67 & 35 & 41 & 0,94 \\
\hline & \multirow{5}{*}{$\begin{array}{l}\text { TRAFO } \\
\text { III } \\
\text { (60MVA) }\end{array}$} & \multirow{5}{*}{20,4} & \multirow{5}{*}{30,33} & \multirow{5}{*}{934} & \multirow{5}{*}{937} & & KBL09 & 24 & 48 & 43 & 0,95 \\
\hline & & & & & & & KBL10 & 172 & 154 & 173 & 0,95 \\
\hline & & & & & & 1010 & KBL12 & 107 & 134 & 154 & 0,95 \\
\hline & & & & & & & KBL13 & 123 & 128 & 150 & 0,95 \\
\hline & & & & & & & KBL14 & 513 & 508 & 500 & 0,95 \\
\hline & & & & & & & KBL06 & 184 & 154 & 173 & 0,95 \\
\hline & TRAFO & & & & & & KBL07 & 85 & 77 & 88 & 0,95 \\
\hline & $\begin{array}{c}\text { III } \\
(60 \mathrm{MVA})\end{array}$ & 20,2 & 13,14 & 442 & 420 & 436 & KBL15 & 80 & 88 & 79 & 0,95 \\
\hline & & & & & & & KBL16 & 91 & 101 & 96 & 0,95 \\
\hline
\end{tabular}

Sumber: APD Purwokerto

Pada Gambar 2 simulasi tersebut, Gardu Induk Kalibakal disuplai dari 2 buah bus line 150 KV dan 3 buah PMT di sisi input. Jika suatu waktu ketika terjadi gangguan pada bus 1 maka bus yang lain dapat mensuplai kebutuhan daya listrik.

\subsection{Skenario Pelepasan Beban Feeder}

Pada perencanaan pelepasan beban dapat ditentukan terlebih dahulu beban-beban yang akan dilepaskan dan dapat dilakukan dengan dua cara yaitu:

\section{a) Manual Load Shedding}

Pelepasan beban secara manual ini akan dilakukan apabila laju penurunan frekuensi sangat rendah, sehingga untuk memperbaiki frekuensi tidak membutuhkan waktu cepat. Hal ini karena sistem dirasa aman untuk jangka waktu cepat karena sistem dirasa aman untuk jangka waktu lama.

b) Automatic Load Shedding

Pelepasan beban otomatis dilakukan ketika laju penurunan frekuensi cukup tinggi. Dengan adanya pepasan beban otomatis maka system secara keseluruhan dapat diselamatkan dengan cepat tanpa harus menunggu operator bekerja. Pelepasan beban otomatis biasanya didukung dengan beberapa komponen, seperti misalnya penggunaan rele frekuensi. Load Shedding adalah proses dimana otoritas listrik menangani kelangkaan daya listrik yang dikonsumsi oleh masyarakat. Pelepasan dilakukan untuk meminimalkan beban yang di konsumsi masyarakat melalui beberapa gardu induk yang terhubung ke pembangkit listrik utama (Rudrapal, Das, Pandey, \& Kar, 2011).

Pada penelitian ini dirancang tiga skenario pelepasan beban berdasarkan data perolehan di lapangan. Adapun skenario yang dirancang adalah:

a) Lepasnya salah satu power grid Gardu Induk Kalibakal

Pada skenario ini, aksi yang dilakukan adalah lepasnya salah satu power grid pada system tenaga listrik Gardu Induk Kalibakal yang dirancang pada detik ke-1 dengan tipe alat PMS/ pemisah sebagai alih hubung jaringan listrik.

b) Lepasnya feeder 11 Gardu Induk Kalibakal

Setelah power grid terbuka, tahap berikutnya menjalankan scenario lepasnya feeder 11 dilakukan pada detik ke-10 dengan tipe alat PMT sebagai saklar lepas beban.

c) Lepasnya feeder 14 Gardu Induk Kalibakal

Setelah kedua skenario dijalankan, berikutnya menjalankan skenario yang ke-3 yaitu lepasnya feeder 14 dengan menggunakan interval waktu pelepasan beban pada detik ke-20 dan tipe alat PMT sebagai pemutus tenaga. 


\subsection{Simulasi Transien pada Feeder}

Pada simulasi tiga skenario tersebut, simulasi dijalankan selama 60 detik. Simulasi ini diambil ketika sistem mengalami gangguan yaitu pada saat lepasnya power grid, lepasnya feeder 11 dan feeder 14. Gambar 3, 4, dan 5 menunjukkan simulasi pelepasan beban.

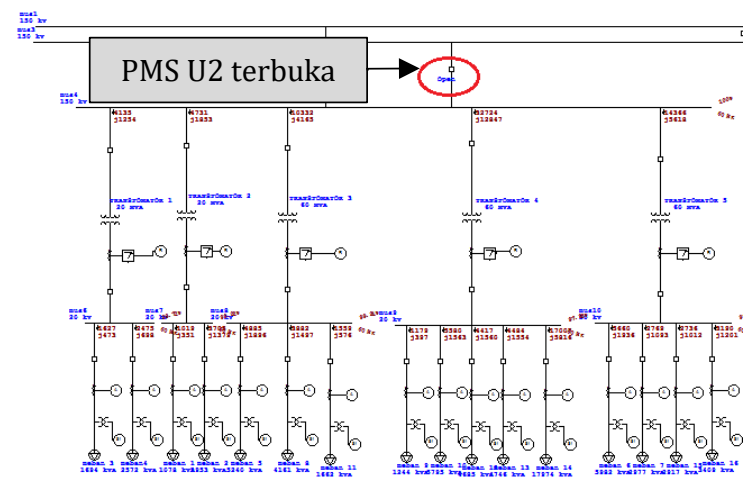

Gambar 3. Simulasi Pelepasan Power Grid (PMS U2 terbuka)

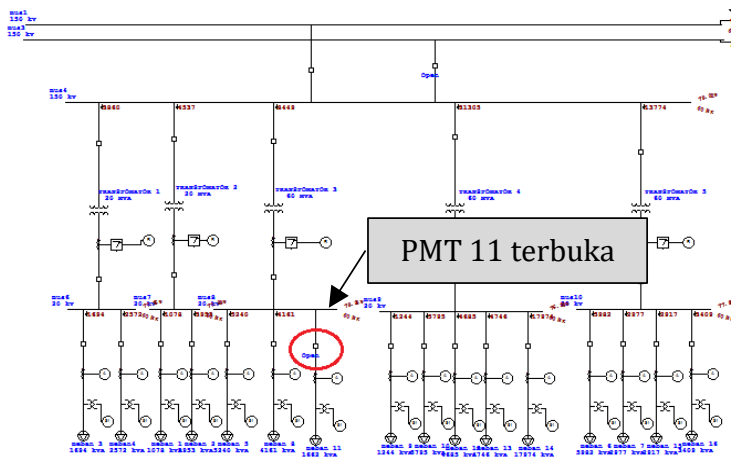

Gambar 4. Simulasi Pelepasan Beban pada Feeder 11 (PMT 11 terbuka)

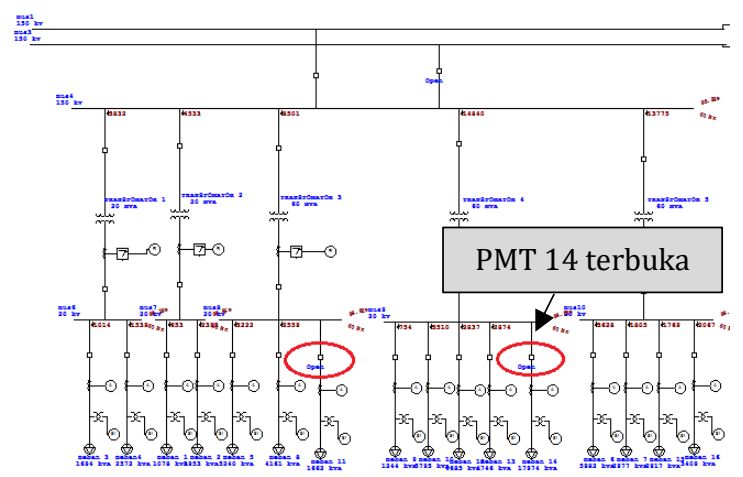

Gambar 5. Simulasi Pelepasan Beban pada Feeder 14 (PMT 14 terbuka)

\subsection{Analisis Hasil}

Pada tahap ini setelah simulasi dan perhitungan selesai dilakukan, langkah berikutnya adalah menganalisis pengaruh pelepasan beban terhadap transien tiap penyulang atau feeder.

\subsection{Monitoring}

Hasil simulasi yang telah diuji dan dianalisis selanjutnya dimonitor kondisi kestabilan transiennya.

Beberapa indeks tambahan yang sering digunakan untuk mengevaluasi keandalan suatu sistem distribusi, yaitu indeks yang berorientasi pada beban yaitu ENS (Energy Not Supplied). Ini didefinisikan sebagai penjumlahan energi tidak diberikan karena gangguan terhadap pasokan daya selama periode tahun. Perhitungan ENS ditunjukkan pada Persamaan (1) berikut (Gerald, Hartati, \& Weking, 2016).

ENS $=\sum$ [Gangguan $(\mathrm{kW}) \times$ Durasi $\left.(\mathrm{h})\right]$

\section{HASIL DAN PEMBAHASAN}

Berikut ini adalah beberapa data hasil simulasi skenario pelepasan beban serta lepasnya power grid pada Gardu Induk Kalibakal.

\subsection{Transien pada saat Power Grid U2 Lepas}

Pada simulasi ini terdapat satu buah power grid yang lepas yaitu U2. Power grid ini mensuplai daya aktif sebesar 33,1 MW dengan MVA short circuit sebesar 149 MVAsc. Kondisi transien terjadi selama 3 detik pada saat salah satu power grid lepas U2 tersebut. Data beberapa komponen sistem tenaga listrik yang diperoleh pada saat simulasi ditunjukkan pada Tabel 2 berikut.

Tabel 2. Perubahan perilaku STL ketika power grid U2 lepas

\begin{tabular}{cccc}
\hline & & $\begin{array}{c}\text { Kondisi } \\
\text { sebelum } \\
\text { gangguan }\end{array}$ & $\begin{array}{c}\text { Kondisi } \\
\text { setelah } \\
\text { gangguan }\end{array}$ \\
\hline $\begin{array}{c}\text { Tegangan } \\
\text { (kV) }\end{array}$ & Suplai & 150 & 132,1 \\
\cline { 2 - 4 } & Beban & 19,8 & 17,4 \\
\hline \multicolumn{2}{c}{ Frekuensi (Hz) } & 50 & 50 \\
\hline
\end{tabular}

Perubahan tegangan sebelum dan setelah mengalami gangguan terlihat signifikan. Turunnya tegangan pada sistem ini akan mempengaruhi kualitas sistem tenaga listrik yang ada. Sedangkan besarnya frekuensi sebelum dan sesudah mengalami gangguan tidak terjadi perubahan. Gambar 6 menunjukan tegangan pada 
bus $150 \mathrm{kV}$ dan bus $20 \mathrm{kV}$ saat power grid lepas dan mengalami transien. Daya yang hilang sebesar 33,1 MW dengan waktu transien selama 3 detik setelah itu kembali ke kondisi steady state.

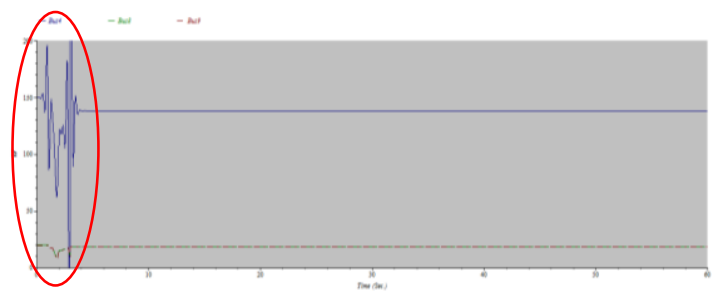

Gambar 6. Bus Voltage pada bus 4, 8, dan 9

Dalam simulasi transient stability analysis, pada detik ke 0-1 sistem masih dalam keadaan stabil. Pada saat diberi gangguan berupa power grid yang lepas di detik ke-1 maka tegangan akan menurun. Pada simulasi ETAP ini pemutusan power grid dilakukan dengan pemutusan PMS U2 pada sisi input Gardu Induk. Sebelum pelepasan, besarnya tegangan pada bus 4 adalah $150 \mathrm{kV}$ sedangkan setelah terjadinya pelepasan tegangan pada sisi input turun menjadi 132,1 kV. Besarnya tegangan pada sisi output bus 8 dan 9 sebelum pelepasan beban adalah sebesar 19,8 $\mathrm{kV}$ dan setelah terjadi pelepasan besar sebesar $17,4 \mathrm{kV}$. Pada saat terjadi transien, tegangan bersifat fluktuatif, hal ini dikarenakan ketidakseimbangan antara beban masukan dan beban keluaran.

\subsection{Transien pada saat power grid dan Feeder 11 Lepas}

Pada skenario tahap kedua Power grid dan PMT pada feeder 11 dilepas, Feeder 11 mensuplai daya sebesar $1559,27 \mathrm{~kW}$, sehingga jumlah beban yang dilepas sebesar 1559,27 KW. Waktu transien saat feeder 11 lepas selama 0,2 detik. Tabel 3 menunjukan data dari beberapa komponen sistem tenaga listrik yang terlihat pada saat dilakukan simulasi.

Tabel 3. Perubahan perilaku STL ketika PMT feeder 11 lepas

\begin{tabular}{cccc}
\hline & & $\begin{array}{c}\text { Kondisi } \\
\text { sebelum } \\
\text { gangguan }\end{array}$ & $\begin{array}{c}\text { Kondisi } \\
\text { setelah } \\
\text { gangguan }\end{array}$ \\
\hline $\begin{array}{c}\text { Tegangan } \\
\text { (kV) }\end{array}$ & Suplai & 150 & 139,3 \\
\cline { 2 - 4 } & Beban & 19,8 & 18,4 \\
\hline \multicolumn{2}{c}{ Frekuensi (Hz) } & 50 & 50 \\
\hline
\end{tabular}

Perubahan tegangan pada saat PMT feeder 11 dilepas pada sisi output akan berangsur-angsur naik. Tahap kedua melepaskan beban sebesar 1559,27 KW. Kondisi ini akan menaikan tegangan pada sisi distribusi. Gambar 7 menunjukkan hasil simulasi perubahan beban perilaku saat PMT feeder 11 lepas. Pada detik ke-10 terjadi kenaikan tegangan $0,4 \%$ pada bus $150 \mathrm{kV}$ dan $20 \mathrm{kV}$ diakibatkan oleh lepasnya beban di feeder 11 sebesar 1,2 kV dari tegangan awal 138,1 kV.

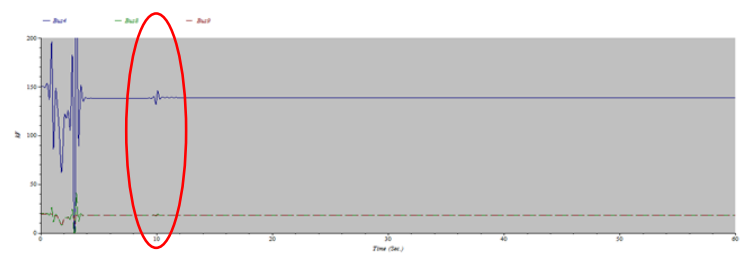

Gambar 7. Bus Voltage pada bus 4, 8, dan 9 feeder 11 lepas

\subsection{Transien pada saat Power Grid, Feeder 14, dan 11 Lepas}

Pada skenario tahap ketiga PMT pada feeder 14, feeder 11 dan power grid dilepaskan. Feeder 14 mensuplai daya sebesar 17007,06 KW dan fedder 11 mensuplai 1559,27 KW, sehingga pada tahap ketiga ini jumlah beban yang dilepaskan adalah sebesar 18566,33 KW. Waktu transien pada saat feeder 14 lepas 0,20 detik. Tabel 4 menunjukan data dari beberapa komponen sistem tenaga listrik yang teramati pada saat dilakukan simulasi.

Tabel 4. Perubahan perilaku STL ketika PMT feeder 14 lepas

\begin{tabular}{cccc}
\hline & & $\begin{array}{c}\text { Kondisi } \\
\text { sebelum } \\
\text { gangguan }\end{array}$ & $\begin{array}{c}\text { Kondisi } \\
\text { setelah } \\
\text { gangguan }\end{array}$ \\
\hline $\begin{array}{c}\text { Tegangan } \\
\text { (kV) }\end{array}$ & Suplai & 150 & 144,4 \\
\cline { 2 - 4 } & Beban & 19,8 & 19,1 \\
\hline \multicolumn{2}{c}{ Frekuensi (Hz) } & 50 & 50 \\
\hline
\end{tabular}

Perubahan tegangan pada saat PMT feeder 11 dan feeder 14 dilepas menunjukkan kenaikan secara berangsur-angsur. Jumlah beban yang dilepaskan pada tahap ini adalah sebesar 18566,33 KW. Hal ini akan menaikan tegangan output sebesar 1,3 KV. Gambar 8 menunjukan sinyal tegangan di bus 150 dan $20 \mathrm{KV}$ mengalami transien dan kenaikan tegangan akibat lepas salah satu power grid dan lepasnya feeder 11 dan 14 di detik ke-10 dan 20. Kondisi transien berlangsung selama 3 detik saat power grid lepas. 


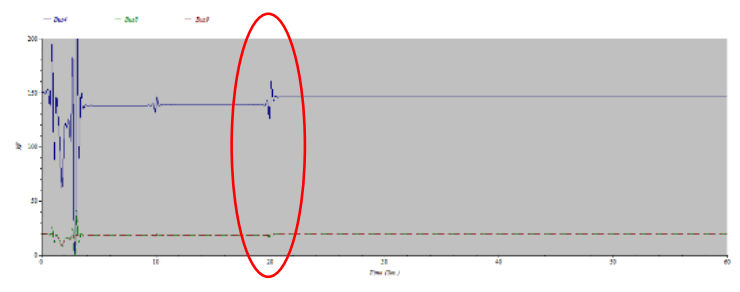

Gambar 8. Voltage pada bus 4, 8, dan 9 feeder 14 lepas

Berdasarkan data yang diperoleh di lapangan bahwa selama bulan Januari-September 2018 terjadi gangguan sebanyak 23 kali. Total kerugian yang dialami PLN akibat adanya gangguan di jaringan listrik sejumlah Rp.2.654.504.265,9. Hal ini menunjukkan bahwa akibat adanya gangguan yang terjadi di tiap penyulang Gardu Induk Kalibakal, PLN mengalami kerugian secara ekonomi. Tabel 5 menunjukkan total kerugian yang dialami PLN.

Tabel 5. Kerugian Biaya PLN selama 23 gangguan

\begin{tabular}{|c|c|c|}
\hline No & Feeder & ENS(Rp)/Hari \\
\hline 1 & KBL04 & Rp. $\quad 48.640 .467,7$ \\
\hline 2 & KBL04 & Rp. $\quad 36.028 .274,2$ \\
\hline 3 & KBL04 & Rp. $116.285 .088,5$ \\
\hline 4 & KBL02 & Rp. $192.826 .926,9$ \\
\hline 5 & KBL09 & Rp. $\quad 84.365 .421,7$ \\
\hline 6 & KBL04 & Rp. $78.643 .665,5$ \\
\hline 7 & KBL13 & Rp. $10.017 .411,4$ \\
\hline 8 & KBL15 & Rp. $\quad 79.355 .706,7$ \\
\hline 9 & KBL07 & Rp. $115.244 .257,9$ \\
\hline 10 & KBL01 & Rp. $\quad 22.410 .004,4$ \\
\hline 11 & KBL04 & Rp. $\quad 31.271 .913,2$ \\
\hline 12 & KBL02 & Rp. $\quad 26.336 .548,1$ \\
\hline 13 & KBL04 & Rp. $\quad 28.531 .719,6$ \\
\hline 14 & KBL15 & Rp. $11.963 .180,4$ \\
\hline 15 & KBL04 & $\begin{array}{ll}\text { Rp. } & 27.901 .827,1 \\
\end{array}$ \\
\hline 16 & KBL11 & Rp. $174.093 .021,0$ \\
\hline 17 & KBL15 & Rp. $\quad 88.321 .574,8$ \\
\hline 18 & KBL05 & Rp. $84.295 .373,2$ \\
\hline 19 & KBL01 & Rp. $\quad 33.859 .142,6$ \\
\hline 20 & KBL02 & Rp. $\quad 63.055 .557,8$ \\
\hline 21 & KBL03 & Rp. $151.523 .358,7$ \\
\hline 22 & KBL12 & Rp.1.095.680.837,2 \\
\hline 23 & KBL03 & Rp. $\quad 57.852 .987,3$ \\
\hline & Total & Rp. 2.654.504.265,9 \\
\hline
\end{tabular}

\section{KESIMPULAN}

Hasil simulasi skenario pertama yang dilakukan pada saat pelepasaan salah satu power grid dengan daya lepas 33,1 MW diperoleh tegangan pulih akibat transien selama 3 detik dengan daya suplai awal sisi input $150 \mathrm{kV}$ menjadi 132,1 kV dan sisi output awal mula 19,8 $\mathrm{kV}$ menjadi $17,4 \mathrm{kV}$. Saat skenario 2 dijalankan yaitu power grid dan feeder 11 lepas dengan waktu tegangan pulih 0,2 detik terjadi kenaikan di sisi input dan output sebesar $139,3 \mathrm{kV}$ dan 18,4 $\mathrm{kV}$, sedangkan pada saat skenario 3 yaitu lepasnya power grid, feeder 11, dan feeder 14 dengan waktu tegangan pulih selama 0,2 detik, kenaikan tegangan di sisi input dan output sebesar 144,4 kV dan 19,1 kV.

Besarnya perubahaan daya yang terlepas tidak berpengaruh pada frekuensi. Frekuensi sebelum dan sesudah terjadi pelepasan beban adalah sama yaitu sebesar $50 \mathrm{~Hz}$. Hasil perhitungan ENS dan harga per KWH Rp. $1.467,28$ pada saat terjadinya gangguan kurang lebih sebanyak 23 gangguan di feeder Kalibakal diperoleh total kerugian sebesar Rp. 2.654.504.265,9 dari pihak PLN.

\section{UCAPAN TERIMA KASIH}

Ucapan terima kasih kami sampaikan kepada Lembaga Penelitian dan Pengabdian pada Masyarakat (LPPM) Universitas Muhammadiyah Purwokerto yang telah membiayai penelitian ini.

\section{DAFTAR PUSTAKA}

Ariansyah, F., Priyadi, A., \& Pujiantara, M. (2016). Analisis Kestabilan Transien dan Pelepasan Beban Pada Sistem Integrasi 33 KV PT . Pertamina RU IV Cilacap Akibat Penambahan Beban RFCC dan PLBC. Jurnal Teknik ITS, 5(1), 19-23.

Defariza, Soeprijanto, A., Lystianingrum, V., \& Putri, B. (2011). Analisis Stabilitas Transien dan Pelepasan Beban Sistem Kelistrikan di PT. PERTAMINA (Persero) R.U. III PlajuSungai Gerong, Palembang. Proceedings Seminar Tugas Akhir Jurusan Teknik Elektro FTI-ITS, 1-12.

Gerald, V., Hartati, R. S., \& Weking, A. I. (2016). Analisisi Energi Listrik Terselamatkan pada Penyulang Bangli PT . PLN ( Persero ) Area Bali Timur dengan Beroperasinya PLTS Kayubihi. Teknologi Elektro, 15(1), 69-74.

Hidayat, S., Priyadi, A., \& Pujiantara, M. (2013). Analisis Kestabilan Transien dan Mekanisme Pelepasan Beban di PT. Pertamina (Perseo) Refinery Unit (R.U.) VI Balongan Jawa Barat. JURNAL TEKNIK POMITS, 1(1), 1-6. 
Popov, E., Yorino, N., Zoka, Y., Sasaki, Y., \& Sugihara, H. (2014). Direct Transient Stability Assessment of Stressed Power Systems, 8(6), 897-904.

Prayitno, A. A. (2013). Analisis Arus Dan Tegangan Transien Akibat Pelepasan Beban Pada Sisi Primer Transformator Unit 5 , Unit 6 , dan Unit 7 Suralaya, 2(1).

Ri'ayatullah, A. Z., \& Waluyo. (2013). Analisis Arus Transien Transformator Setelah Penyambungan Beban Gedung Serbaguna PT “ X.” Jurnal Reka Elkomika, 1(1), 1-10.

Rudrapal, D., Das, S., Pandey, A., \& Kar, N. (2011).
Automated Load Shedding Period Control System, 3(5).

Tambunan, R. P. T., Karnoto, K., \& Handoko, S. (2014). Simulasi Pelepasan Beban (Load Shedding) pada Sistem Jaringan Distribusi Tragi Sibolga 150/20 KV (Studi Kasus pada Penyulang Tragi Sibolga, SUMUT). TRANSIENT, 3(2), 212-217.

Winarso, W., \& Yunarto, Y. (2017). Analisa dan Simulasi Stabilitas Transien dengan Pelepasan Beban pada Sistem Pembangkit Tenaga Listrik. Dinamika Rekayasa, 13(2), 61-68 